\title{
KAJIAN STRATEGI PENGEMBANGAN AGROWISATA KOPI LUWAK (STUDI KASUS KOPI LUWAK MANGLAYANG, KAMPUNG PONDOK BUAHBATU-CIKAWARI, DESA MEKARMANIK, KECAMATAN CIMENYAN, KABUPATEN BANDUNG) \\ Lucyana Trimo ${ }^{1}$, Gema Wibawa Mukti ${ }^{2}$, Fauziana $\mathrm{H}^{3}$ \\ 1,2,3Program Studi Agribisnis Departemen Sosial Ekonomi Pertanian \\ Fakultas Pertanian Universitas Padjadjaran \\ E-mail: lucy.trimo@gmail.com; lucyana.trimo@unpad.ac.id
}

\begin{abstract}
ABSTRAK
Kelompok Usaha Kopi Luwak Manglayang (KLM) berusaha mengembangkan agrowisata kopi luwak dengan menerapkan kaidah kesejahteraan hewan di kawasan kaki Gunung Manglayang, namun saat ini belum dikembangkan secara optimal. Penelitian dilakukan pada kelompok usaha KLM, di kaki Gunung Manglayang. Desain penelitian yang digunakan adalah kualitatif dengan teknik penelitian studi kasus. Rancangan analisis data yang digunakan adalah analisis deskriptif kualitatif, analisis matriks IFE, analisis matriks EFE, dan analisis SWOT. Dari hasil penelitian yang telah dilakukan diketahui bahwa kegiatan agrowisata kopi luwak yang telah dilakukan oleh KLM mulai dari edukasi mengenai proses produksi kopi luwak dengan menerapkan kaidah kesejahteraan satwa hingga wisata kuliner. Strategi yang telah dilakukan oleh KLM dalam pengembangan agrowisata kopi luwak adalah membuat rencana dalam perbaikan fasilitas di lokasi KLM, meningkatkan cita rasa kopi yang dihasilkan oleh KLM, dan melakukan promosi agrowisata KLM melalui media sosial. Strategi yang paling tepat dan diutamakan dalam pengembangan agrowisata KLM yaitu strategi agresif dengan meningkatkan berbagai daya tarik agrowisata KLM serta memperluas pemasaran agrowisata KLM.
\end{abstract}

Kata kunci: agrowisata, strategi pengembangan, analisis SWOT

\section{ABSTRACT}

Kelompok Usaha Kopi Luwak Manglayang (KLM) trying to develop civet coffee agrotourism by applying animal welfare rules in the Manglayang Mountain, but currently it has not been optimally developed. The study was conducted at Kelompok Usaha Kopi Luwak Manglayang (KLM), at Manglayang Mountain. The research design used is qualitative with case study research techniques. The data analysis design used qualitative descriptive analysis, IFE matrix analysis, EFE matrix analysis, and SWOT analysis. The results showed that the civet coffee agrotourism activities conducted by KLM started from education about the production process of civet coffee by applying animal welfare principles to culinary tourism. Strategies that have been made by KLM in the development of agro civet coffee is making plans in facility improvements at the site of KLM, enhance the flavor of the coffee produced by KLM and KLM agrotourism promotion through social media. The most appropriate strategy and priority in the development of agro-KLM is an aggressive strategy to increase the variety of agro-tourism appeal and expand marketing agro KLM KLM.

Keywords : agrotourism, development strategy, SWOT analysis 


\section{PENDAHULUAN}

Indonesia merupakan suatu negara agraris yang memiliki potensi alam yang dapat dikembangkan sebagai daya tarik potensial untuk pengembangan pariwisata. Sektor pariwisata merupakan salah satu sektor yang saat ini sedang di galakkan oleh pemerintah. Hal ini disebabkan karena pariwisata mempunyai peran yang sangat penting dalam pembangunan Indonesia khususnya sebagai penghasil devisa negara. Berdasarkan data yang dilaporkan oleh Badan Pusat Statistik, tahun 2014 sektor pariwisata menciptakan devisa sebesar US\$11,17 miliar, meningkat dari US\$ 10,05 miliar di tahun 2013

(Kementerian Pariwisata Republik Indonesia, 2014). Dalam laporan kinerja Kementerian Pariwisata diketahui pula bahwa dampak kepariwisataan di Indonesia terhadap Produk Domestik Bruto (PDB) nasional di tahun 2014 sebesar Rp 391,49 triliun atau sebesar 4,01\% dari PDB nasional (Grafik 1). Selanjutnya, berdasarkan Grafik tersebut dapat diketahui pula bahwa PDB pariwisata lima tahun terakhir (2010-2014) mengalami peningkatan.

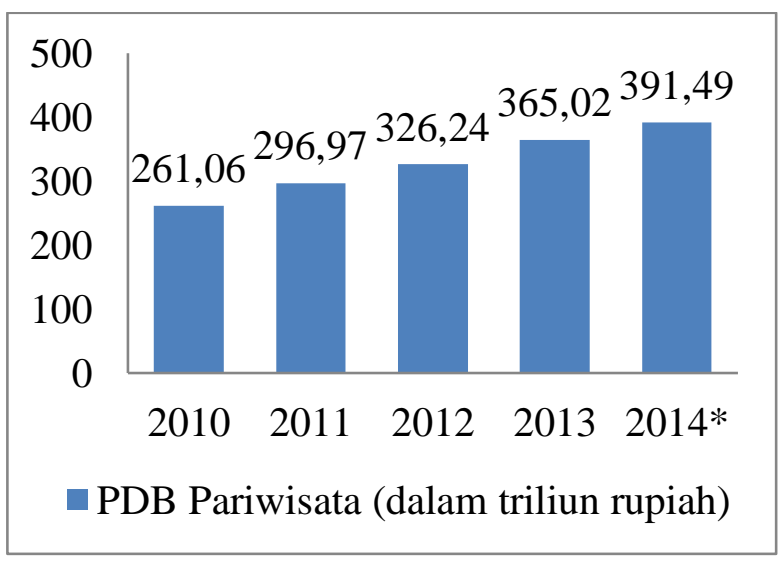

Gambar 1. Peningkatan PDB Pariwisata

(Kementerian Pariwisata, 2014)

Keterangan: *) Angka Sementara
Potensi pertumbuhan sektor pariwisata di Provinsi Jawa Barat dapat dilihat dari kunjungan turis mancanegara dan nusantara yang datang ke objek wisata. Pada tahun 2015, jumlah wisatawan ke objek wisata di Provinsi Jawa Barat mencapai 33.381.064 orang dengan Kabupaten Bandung yang merupakan salah satu kabupaten di Provinsi Jawa Barat yang paling banyak dikunjungi oleh wisatawan mancanegara maupun nusantara. Hal tersebut terjadi karena Kabupaten Bandung memiliki berbagai objek wisata seperti wisata alam dan wisata budaya yang menjadi daya tarik bagi wisatawan (Dinas Pariwisata dan Kebudayaan Provinsi Jawa Barat, 2014). Salah satu kegiatan pariwisata yang sedang berkembang dan menjadi tren saat ini adalah agrowisata yang merupakan bentuk pariwisata dengan mengembangkan dan memanfaatkan potensi keindahan sektor pertanian, agribisnis, dan perkebunan. Jenis pariwisata ini juga menguntungkan dari segi ekonomi namun tetap berorientasikan kelestarian lingkungan.

Kecamatan Cimenyan merupakan salah satu wilayah pegunungan atau daerah perbukitan di Kawasan Bandung Utara, Kabupaten Bandung, Provinsi Jawa Barat. Di kecamatan tersebut, terdapat salah satu usaha agribisnis kopi khususnya kopi luwak di mana jenis kopi tersebut saat ini sedang menjadi tren baik nasional maupun internasional. Kopi luwak tidak berasal dari spesies kopi khusus, namun berasal dari hasil fermentasi di dalam perut musang luwak (Paradoxurus hermaphroditus) yang dikeluarkan bersama kotoran dalam bentuk biji.

Kopi Luwak Manglayang (KLM) merupakan usaha agribisnis kopi luwak di 
Kecamatan Cimenyan yang mulai mengembangkan usaha agribisnisnya dengan memproduksi kopi luwak yang menerapkan kaidah kesejahteraan satwa (animal welfare) pada proses pemeliharaan luwak untuk produksi kopi luwak sejak tahun 2013. Penerapan kaidah kesejahteraan satwa dilakukan dalam rangka menghapus anggapan adanya pelanggaran hak kesejahteraan hewan dan mengeksploitasi luwak dengan mengurung dan memaksa musang luwak memakan biji kopi untuk kemudian menghasilkan jenis kopi luwak. KLM yang telah menerapkan kaidah tersebut, ikut bergabung dalam Tim Satwa Kita pada tahun 2014, dan telah mendapatkan pengakuan resmi dari Deddy Mizwar, Wakil Gubernur Jawa Barat pada tahun 2015.

Kopi luwak yang diproduksi oleh KLM memiliki beragam varian mulai dari green bean hingga kopi luwak bubuk yang di roasting dengan standar medium roast sehingga memiliki karakter rasa low acid, smooth, caramely, dan chocolaty. Selain itu, saat ini KLM juga memproduksi kopi reguler dengan merk Manglayang Karlina yang memiliki rasa manis yang khas seperti rasa buah strawberry.

Sejak tahun 2014, KLM juga menjadi salah satu objek wisata di kawasan kaki Gunung Manglayang tetapi baru sebatas pemanfaatan view akan kebun kopi, kandang luwak, saung, dan kolam pemancingan ikan. Kegiatan wisata yang pernah dilakukan KLM dimulai dari mengelilingi kebun kopi sambil diberikan edukasi mengenai budidaya tanaman kopi, menanam bibit kopi, memetik buah kopi, luwak feeding, foto bersama luwak, melihat proses pembuatan kopi luwak dengan menerapkan kaidah kesejahteraan satwa, dan mencicipi kuliner sederhana yang disajikan.

Berdasarkan data yang diperoleh dari Dinas Perkebunan serta Dinas Pariwisata dan Kebudayaan Provinsi Jawa Barat pada tahun 2012-2014 diketahui bahwa agrowisata yang terdapat di Kabupaten Bandung paling banyak merupakan agrowisata teh, sedangkan agrowisata kopi luwak masih sangat sedikit. Hal ini dijadikan suatu kesempatan oleh KLM untuk meningkatkan jumlah wisatawan dengan mengembangkan agrowisata kopi luwak. Adanya kunjungan wisatawan nusantara maupun mancanegara, dan adanya paket wisata yang pernah dilakukan oleh KLM, menunjukkan bahwa KLM memiliki daya tarik untuk dikembangkan menjadi kawasan agrowisata kopi luwak. Walaupun demikian, ternyata kegiatan wisata di KLM ini belum dapat dikatakan berkembang karena belum diiringi oleh ketersediaan infrastruktur dasar dan sarana prasarana pariwisata yang cukup, seperti rest area, MCK, tempat belanja, sistem jalan, sistem telekomunikasi, dan lain sebagainya. Berdasarkan uraian di atas, maka perlu diteliti potensi apa saja yang dimiliki pleh KLM, dan bagaimana strategi yang harus dilakukan agar KLM menjadi sebuah sgrowisata yang dapat diandalkan dimasa mendatang.

\section{METODE PENELITIAN}

Tempat penelitian dipilih secara sengaja (purposive) dengan pertimbangan bahwa KLM (kopi Luwak Manglayang) merupakan salah satu usaha budidaya kopi luwak dengan menerapkan kaidah kesejahteraan satwa (animal welfare) dan telah mendapatkan pengakuan dari wakil gubernur Jawa Barat, H. Deddy Mizwar. 
Desain penelitian yang digunakan pada penelitian ini adalah kualitatif dengan teknik penelitian studi kasus (case study). Data primer diperoleh melalui wawancara secara langsung kepada para informan yang dipilih secara sengaja (purposive) dan ditentukan dengan menggunakan teknik snowball sampling, yaitu: pemilik agribisnis KLM, pekerja di KLM (seperti CEO, manajer operasional), petani kopi luwak, tokoh masyarakat atau budayawan setempat, serta aparat pemerintah setempat. Selain itu, wawancara juga dilakukan terhadap wisatawan dengan menggunakan teknik penentuan sampel berdasarkan kebetulan (incidental sampling). Teknik yang digunakan dalam pengumpulan data dilaksanakan dengan menggunakan teknik triangulasi (Gambar 2). Selanjutnya, data sekunder diperoleh dari Dinas Perkebunan Provinsi Jawa Barat, Dinas Pariwisata dan Kebudayaan Provinsi Jawa Barat, Direktorat Jendral Perkebunan, Kementrian Perkebunan, Badan Pusat Statistik, dan studi pustaka atau laporan-laporan dari lembaga atau instansi terkait.

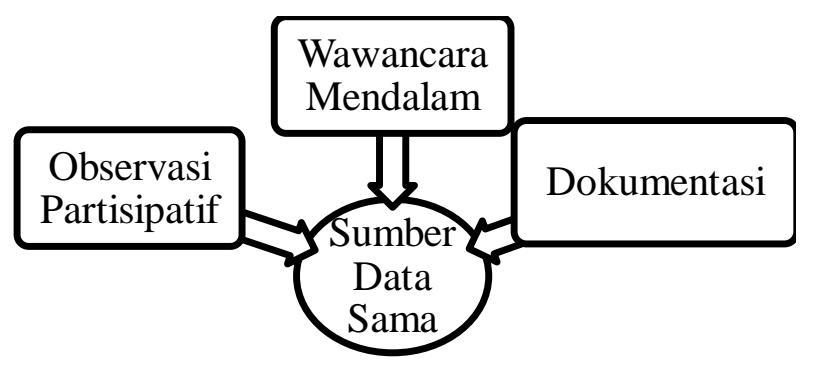

Gambar 2. Triangulasi "Teknik"

Pengumpulan Data (Sugiono, 2011)

Data dari hasil lapangan, dianalisis dengan secara deskriktif kualitatif. Dalam Ramadhan (2013) dijelaskan bahwa analisis deskriptif kualitatif adalah cara untuk mencari hubungan secara menyeluruh dan teliti dari suatu keadaan, kemudian untuk merumuskan dan menfasirkan data yang ada sehingga memberikan gambaran dan informasi yang jelas. Selanjutnya, untuk merumuskan strategi pengembangan KLM maka digunakan analisa matriks IFE (Internal Faktor Evaluation), EFE (Eksternal Faktor Evaluation), dan analisis SWOT. Melalui matriks SWOT dapat menggambarkan secara jelas bagaimana peluang dan ancaman yang dihadapi perusahaan dapat dihadapi dengan menggunakan kekuatan dan kelemahan yang dimilikinya. Matriks ini dapat menghasilkan empat set kemungkinan alternatif strategis.

\section{HASIL DAN PEMBAHASAN}

\section{Kondisi Umum KLM}

Kopi Luwak Manglayang (KLM) adalah suatu usaha agribisnis kopi khususnya kopi luwak yang memiliki luas lahan seluas 2 hektar di kaki Gunung Manglayang tepatnya di Kampung Pondok BuahbatuCikawari, Desa Mekarmanik, Kecamatan Cimenyan, Kabupaten Bandung, Jawa Barat pada ketinggian $1.200 \mathrm{~m}$ dpl. Pada tahun 2005, lahan seluas 2 hektar ini dimulai dengan budidaya buah-buahan dan kayu-kayuan sebagai tanaman penaung. Awalnya, usaha agribisnis ini dibentuk bukan untuk usaha melainkan karena hobi dari pemilik KLM, Hermin Karlina, dalam melakukan budidaya tanaman dan sebagai bentuk keprihatinan terhadap lingkungan di sekitar kawasan Gunung Manglayang yang mayoritas lahannya merupakan lahan kritis dengan ditanami tanaman sayuran dimana komoditas tersebut menjadi salah satu penyebab terjadinya bencana longsor pada musim hujan di kawasan tersebut. Hal ini terjadi karena tanaman sayuran yang dibudidayakan di kawasan Gunung 
Manglayang tidak memiliki akar yang kuat untuk dijadikan sebagai penahan air hujan.

Selain itu, berdasarkan data dari Badan Perencanaan Lingkungan Hidup Daerah (BPLHD) tahun 2012, kondisi mata air di Desa Mekarmanik mengalami penurunan, sekitar tiga dari enam belas mata air menghilang akibat adanya kegiatan penambangan di daerah tersebut. Pada tahun 2010, komoditas perkebunan seperti tanaman kopi pun mulai dibudidayakan di kebun KLM dengan tujuan mengajak para petani sayuran di kawasan tersebut untuk mengubah pola pikirnya agar mau beralih ke komoditas perkebunan khususnya kopi dalam rangka mencegah terjadinya bencana longsor dengan cara membagikan bibit kopi secara gratis untuk dibudidayakan di lahan para petani tersebut, mengembalikan sumber mata air, dan dapat meningkatkan kesejahteraan petani di kawasan Gunung Manglayang. Budidaya tanaman kopi yang dipadukan dengan tanaman buah-buahan dan kayukayuan di kebun KLM ternyata memberikan dampak positif yaitu sumber air di kawasan tersebut tetap mengalir meskipun di saat kemarau.

Pada tahun 2013, KLM mulai mengembangkan usaha agribisnisnya dengan memproduksi kopi luwak. KLM menerapkan kaidah kesejahteraan satwa (animal welfare) dalam proses produksi kopi luwak. Hal tersebut dibuktikan dengan melakukan manajemen kandang dan pakan. Manajemen kandang dilakukan dengan pemeliharaan luwak yang mengikuti kaidah kesejahteraan satwa seperti adanya dua jenis kandang luwak yang terdiri dari satu buah kandang terbuka dan satu buah kandang tertutup. Bentuk kandang dibuat luas dan nyaman dengan menggunakan sistem sanitasi kandang optimal agar luwak dapat bergerak secara leluasa. Selain itu, kandang dibuat tinggi yaitu 3 m dengan menempatkan tangga dan jembatan dari kayu yang menyerupai pohon untuk menyesuaikan kondisi alami tempat tinggal luwak.

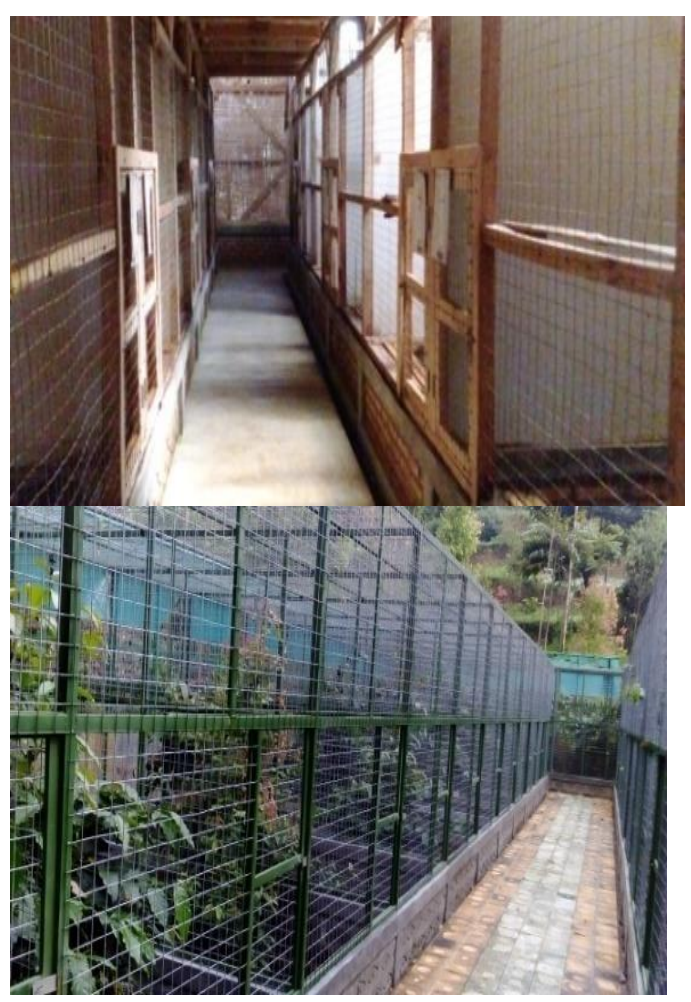

Gambar 3. Kandang Luwak Tertutup (Kiri) dan Kandang Luwak Terbuka (Kanan)

Kandang luwak dibersihkan setiap pagi hari agar luwak yang dikembangbiakan dapat terbebas dari rasa sakit, luka, dan penyakit. Luwak yang dikembangbiakan tidak dipaksa untuk mengonsumsi kopi agar luwak tersebut dapat terhindar dari rasa stres dan tertekan.

Pada tahun 2014, KLM tergabung dalam Tim Satwa Kita yang berperan sebagai pendamping dalam pembuatan kandang, manajemen kandang, dan manajemen pakan luwak. Dalam manajemen pakan luwak, KLM telah memenuhi syarat yang 
disesuaikan dengan habitat alaminya yaitu memberikan pakan luwak sebanyak dua kali sehari pada sore dan malam hari yang terdiri dari pakan daging (kornet), buahbuahan (pisang, pepaya, mangga, rambutan, dan salak), kopi, dan air bersih. Pada tahun ini pula, KLM menjadi salah satu objek wisata di kawasan kaki Gunung Manglayang tetapi baru sebatas pemanfaatan view akan kebun kopi, kandang luwak, saung, dan kolam ikan. Pada bulan November 2015, KLM sedang dalam proses pembuatan usaha Perseroan Komanditer (Commanditaire

Vennootschap atau CV) agar menjadi suatu badan hukum yang legal dengan menggunakan nama CV. Kiwari Farmers yang berarti petani modern.

\section{Bidang Usaha KLM}

Kopi luwak yang diproduksi oleh KLM memiliki beragam varian mulai dari green bean hingga kopi luwak bubuk yang di roasting dengan standar medium roast sehingga memiliki karakter rasa low acid, smooth, caramely, dan chocolaty. Selain memproduksi kopi luwak, KLM juga memproduksi kopi reguler dengan merk Manglayang Karlina yang diambil dari nama pemilik KLM yaitu Hermin Karlina dan adanya rasa manis yang khas seperti rasa buah strawberry di dalam kopi reguler Manglayang tersebut. Kopi reguler Manglayang Karlina ini diproduksi dalam bentuk green bean dan telah mendapatkan juara kedua dalam kompetisi Golden Cup di ajang West Java Coffee Festival yang diselenggarakan oleh Dinas Perdagangan dan Perindustrian Provinsi Jawa Barat pada bulan November 2015. KLM juga sudah mulai bekerja sama dengan Universitas Padjadjaran dalam salah satu program unggulan UNPAD yaitu Locarvest (Local
Farmer's Harvest) dan beberapa cafe di Bandung seperti Armor Kopi Bandung sebagai penyuplai utama berbagai kopi yang diproduksinya, Morning Glory dan Yellow Truck.

\section{Potensi Agrowisata yang dimiliki KLM}

Pada awalnya, kegiatan wisata ini dilakukan karena adanya keinginan pecinta kopi luwak yang penasaran dengan cara pembuatan kopi luwak yang diproduksi oleh KLM. Selain itu, KLM juga sering dijadikan rekomendasi oleh Dinas Perindustrian dan Perdagangan Provinsi Jawa Barat sebagai salah satu usaha agribisnis kopi luwak di Kabupaten Bandung yang memiliki kebun kopi beserta kandang luwaknya di lokasi yang sama, dan telah mengikuti kaidah kesejahteraan satwa sehingga KLM sering dikunjungi oleh wisatawan nusantara dan mancanegara seperti Amerika, Meksiko, Bangladesh, Madagaskar, Poland, Swedia, Korea, dan Cina.

\section{Obyek Wisata yang dimiliki KLM}

Kegiatan wisata yang dilakukan KLM adalah: (1) mengelilingi kebun kopi seluas 2 hektar sambil diberikan pengarahan dan edukasi mengenai budidaya tanaman kopi mulai dari penyiapan lahan dan pohon penaung, pembibitan tanaman kopi, pemeliharaan tanaman kopi (penyulaman, pemupukan, dan pemangkasan), pengendalian hama dan penyakit pada tanaman kopi, dan panen. Selain itu, wisatawan diajak untuk menanam bibit kopi di lahan yang telah disediakan KLM dalam rangka membantu melestarikan lingkungan kawasan Gunung Manglayang dan menjadi kenang-kenangan bagi wisatawan maupun KLM. (2) melihat kandang luwak terbuka dan kandang luwak tertutup sambil berinteraksi secara langsung dengan luwak yang 
dikembangbiakan oleh KLM. Wisatawan diberikan edukasi mengenai cara mengembangbiakan luwak mulai dari pembuatan kandang, manajemen kandang, dan manajemen pakan luwak. Selain itu, wisatawan juga dapat ikut serta memberikan pakan luwak seperti nasi, kornet, dan buah-buahan, serta dapat berfoto bersama luwak-luwak tersebut. (3) edukasi mengenai proses produksi kopi luwak dengan menerapkan kaidah kesejahteraan satwa. (4) wisata kuliner, yaitu berupa sajian kopi luwak hangat sebagai cupping test, makanan ringan, dan makanan khas sunda sebagai makan siang. Wisatawan dapat menikmati hidangan kuliner tersebut di saung yang terdapat di sekitar kebun kopi sambil menikmati pemandangan kebun kopi dan suara gemercik dari kolam ikan sebesar 15x12x1 m. Selain itu, terdapat atraksi wisata yang terdapat dimasyarakat sekitar wilayah KLM yaitu: kuda renggong, marawis, pencak silat, dan sisingaan.

\section{Sarana Pelengkap dan} Penunjang Obyek Wisata di KLM

Fasilitas rekreasi yang ada di KLM, adalah: (1) kolam pemancingan ikan yang dapat dinikmati oleh para wisatawan yang memiliki hobi memancing ikan sebagai salah satu kegiatan yang menyenangkan dan dapat menenangkan pikiran dan (2) kandang hewan ternak seperti ayam, kambing, dan kelinci, disini wisatawan juga dapat bermain dengan hewan ternak tersebut sambil memberi pakan yang telah disediakan dan berfoto bersama kelinci.

Sarana pelengkap lainnya, yang dimiliki KLM, yaitu: (1) letak kebun kopi yang berada di lembah menyebabkan wisatawan harus menuruni 119 anak tangga untuk sampai ke kebun kopi di KLM, ini menjadi salah satu daya tarik bagi wisatawan.

Setelah melewati anak tangga, wisatawan juga harus menyebrangi saluran sungai kecil buatan dengan jembatan yang terbuat dari bambu yang dilengkapi pegangannya, hal ini menambah daya tarik bagi wisatawan, karena wisatawan dapat melihat arus air sungai kecil buatan tersebut sekaligus menikmati keindahan kebun kopi di KLM. (2) Adanya listrik dan air bersih yang bersumber dari mata air yang terdapat di Gunung Manglayang. (3) KLM menyediakan sebuah saung yang dapat digunakan sebagai tempat menginap para wisatawan tersebut. (4) Tersedianya mushola dan mck (mandi, cuci dan kakus). (5) jalan raya yang semakin menyempit pada saat menuju KLM, dan (6) kendaraan motor (ojek), srta (7) rumah dan villa milik penduduk yang dapat dimanfaatkan sebagai penginapan.

\section{Strategi Pengembangan Agrowisata KLM}

Strategi yang tepat untuk pengembangan agrowisata KLM berdasarkan faktor kekuatan, kelemahan, peluang, dan ancaman yang telah dianalisis melalui matriks IFE dan EFE, dapat dilihat dalam Tabel Matrik SWOT berikut: 


\section{Matriks SWOT}

\begin{tabular}{|c|c|c|}
\hline EFE & $\begin{array}{l}\text { Kekuatan (S) } \\
\text { 1. Tenaga kerja KLM mampu } \\
\text { menerima wisatawan dengan } \\
\text { baik. } \\
\text { 2. Terdapat wisata kuliner dan } \\
\text { cupping test. } \\
\text { 3. Objek wisata yang } \\
\text { ditawarkan bersifat rekreasi } \\
\text { yang edukatif. } \\
\text { 4. Terdapat fasilitas rekreasi. } \\
\text { 5. Kebun KLM cocok sebagai } \\
\text { tempat menenangkan diri } \\
\text { dan refreshing. } \\
\text { 6. Terdapat berbagai objek } \\
\text { wisata pendukung. } \\
\text { 7. Promosi yang dilakukan dari } \\
\text { mulut ke mulut (word of } \\
\text { mouth) dan melalui media } \\
\text { sosial. }\end{array}$ & $\begin{array}{l}\text { Kelemahan (W) } \\
\text { 1. Jabatan pengelola KLM masih } \\
\text { merangkap dan belum } \\
\text { memiliki tenaga kerja yang } \\
\text { bertanggung jawab sebagai } \\
\text { pramuwisata. } \\
\text { 2. Terbatasnya dana dalam } \\
\text { mengembangkan agrowisata } \\
\text { KLM. } \\
\text { 3. Prasarana umum di KLM } \\
\text { masih belum lengkap. } \\
\text { 4. Belum memiliki sarana } \\
\text { penunjang di sekitar KLM. } \\
\text { 5. Sarana transportasi umum } \\
\text { menuju KLM masih kurang } \\
\text { memadai. } \\
\text { 6. Kurangnya atraksi wisata yang } \\
\text { ditawarkan oleh KLM. } \\
\text { 7. Masyarakat sekitar belum } \\
\text { dapat menerima wisatawan } \\
\text { dengan baik. }\end{array}$ \\
\hline $\begin{array}{l}\text { Peluang (O) } \\
\text { 1. Masyarakat siap untuk } \\
\text { bekerjasama dengan } \\
\text { agrowisata KLM dalam } \\
\text { menampilkan atraksi } \\
\text { wisata. } \\
\text { 2. Lokasi kebun KLM dekat } \\
\text { dengan pusat kota. } \\
\text { 3. Dapat berkolaborasi } \\
\text { dengan berbagai objek } \\
\text { wisata pendukung di } \\
\text { Kawasan Gunung } \\
\text { Manglayang. } \\
\text { 4. Terdapat dukungan } \\
\text { pemerintah dalam } \\
\text { pengembangan agrowisata. }\end{array}$ & $\begin{array}{l}\text { S-O } \\
\text { 1. Meningkatkan berbagai daya } \\
\text { tarik agrowisata KLM. } \\
\text { (S1, S2, S3, S4, S5, S6, S7, } \\
\text { O1, O2, O3, O4) } \\
\text { 2. Memperluas pemasaran } \\
\text { agrowisata KLM. } \\
\text { (S1, S2, S3, S4, S5, S6, S7, } \\
\text { O1, O2, O3) }\end{array}$ & $\begin{array}{l}\text { W-O } \\
\text { 1. Meningkatkan sarana dan } \\
\text { prasarana yang mendukung } \\
\text { kegiatan agrowisata KLM. } \\
\text { (W2, W3, W4, W5, W6, O1, } \\
\text { O4) } \\
\text { 2. Memberikan penyuluhan } \\
\text { kepada masyarakat. } \\
\text { (W1, W7, O1) }\end{array}$ \\
\hline Ancaman (T) & S-T & W-T \\
\hline
\end{tabular}




\begin{tabular}{|l|l|l|}
\hline $\begin{array}{l}\text { 1. Masuknya pendatang baru } \\
\text { agrowisata sejenis di } \\
\text { daerah Kabupaten }\end{array}$ & $\begin{array}{l}\text { 1. Menjalin kerja sama dengan } \\
\text { biro perjalanan wisata atau } \\
\text { travel dan berbagai cafe } \\
\text { yang menyediakan kopi } \\
\text { dalam menunya untuk }\end{array}$ & $\begin{array}{l}\text { Merekrut profesional } \\
\text { pengelola pariwisata ke dalam } \\
\text { manajemen pengelola } \\
\text { agrowisata. } \\
\text { 2. Adanya peningkatan harga } \\
\text { sarana dan faktor produksi } \\
\text { dalam usahatani atau } \\
\text { budidaya tanaman kopi. } \\
\text { menarik lebih banyak }\end{array}$ \\
$\begin{array}{l}\text { 3. Sulitnya menemukan } \\
\text { wisatawan yang sesuai } \\
\text { dengan segmentasi pasar } \\
\text { yang telah ditentukan. }\end{array}$ & (S2, S3, S4, S5, S7, T1, T3) & $\begin{array}{l}\text { 2. Memberi pelatihan kepada } \\
\text { setiap tenaga kerja dan } \\
\text { masyarakat sekitar yang turut } \\
\text { serta mengembangkan } \\
\text { agrowisata KLM untuk } \\
\text { meningkatkan kemampuan } \\
\text { dalam mengelola agrowisata } \\
\text { dan menghadapi persaingan. }\end{array}$ \\
& & (W1, W3, W4, W5, W6, W7, \\
& & T1, T2) \\
\hline
\end{tabular}

Berdasarkan analisis matriks IFE matriks EFE, dapat diketahui pula bahwa nilai total skor yang diperoleh dari masing-masing faktor adalah:

Faktor kekuatan (strengths) : 2,035

Faktor kelemahan (weaknesses) 0,743

Faktor peluang (opportunities) : 2,426

Faktor ancaman (threats) $\quad: 1,072$

Selisih dari faktor internal yang terdiri dari kekuatan dan kelemahan adalah sebesar 1,292 yang didominasi oleh kekuatan. Sedangkan selisih dari faktor eksternal yang terdiri dari peluang dan ancaman adalah sebesar 1,354 yang didominasi oleh peluang. Nilai skor pada kekuatan dan peluang menjadi koordinat posisi strategi perusahaan yang tepat yaitu pada koordinat $\mathrm{X}=1,292$ dan $\mathrm{Y}=1,354$, yang selanjutnya dimasukkan ke dalam diagram SWOT, sehingga dapa dalam t diketahui posisi agrowisata KLM (Gambar 4):

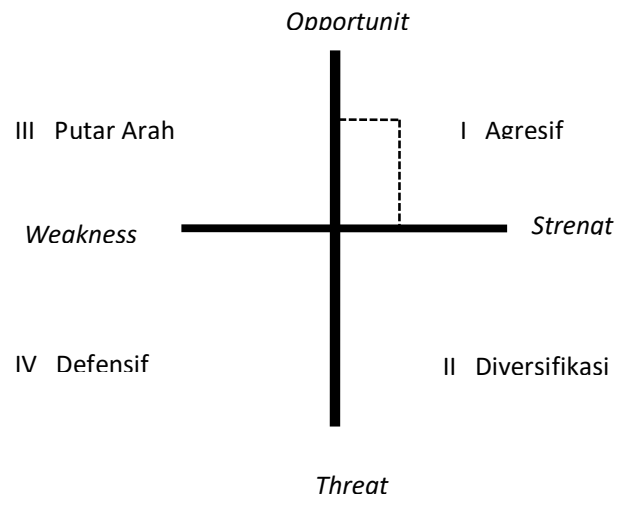

Gambar 4. Posisi Agrowisata KLM Berdasarkan Gambar 4 dapat diketahui bahwa agrowisata KLM berada pada posisi kuadran I (satu) yaitu strategi S-O atau agresif. Oleh karena itu, strategi yang tepat dan diutamakan dalam melakukan upaya pengembangan agrowisata KLM adalah meningkatkan berbagai daya tarik agrowisata KLM dan memperluas pemasaran agrowisata KLM. Strategi untuk meningkatkan daya tarik agrowisata KLM dapat dilakukan dengan merancang paket wisata dengan menambahkan beberapa paket wisata yang disediakan oleh agrowisata KLM. Sedangkan strategi untuk memperluas pemasaran agrowisata KLM dapat dilakukan dengan melakukan 
kerja sama dengan berbagai objek wisata pendukung.

\section{SIMPULAN DAN REKOMENDASI}

KLM mempunyai potensi agrowisata yang cukup baik, namun terdapat pula beberapa kelemahan, seperti: keterbatasan dana, kurangnya sarana dan prasarana penunjang, serta kurangnya atraksi wisata yang ditawarkan. Faktor kekuatan agrowisata KLM yang paling menonjol adalah objek wisata yang ditawarkan bersifat rekreasi yang edukatif.

Strategi yang paling tepat dan diutamakan dalam pengembangan agrowisata KLM yaitu strategi agresif dengan meningkatkan berbagai daya tarik agrowisata KLM serta memperluas pemasaran agrowisata KLM.

\section{DAFTAR PUSTAKA}

Adnyani, Ni Nym Dewi, Ni Wyn Sukerti, dan Luh Masdarini. 2015. Strategi Pengembangan Agrowisata Salak di Desa Sibetan Kabupaten Karangasem. Dalam http://ejournal.undiksha.ac.id/index.php/ JJPKK/article/view/4784. Diakses pada tanggal 01 Januari 2016 pukul 18.11 WIB.

Andini, Nurulitha. 2013. "Pengorganisasian Komunitas Dalam Pengembangan Agrowisata di Desa Wisata (Studi Kasus: Desa Wisata Kembangarum, Kabupaten Sleman)." Perencanaan Wilayah dan Kota, Vol. 24, No. 3.

Ansofino. 2013. Pengembangan Kawasan Agrowisata BBI Lubuak Minturun sebagai Destinasi Utama Pariwisata Sumatera Barat. "Economica, Jurnal
Program Studi Pendidikan Ekonomi STKIP PGRI Sumatera Barat", Vol. 1, No. 2.

Arminsyurita. 2014. Analisis Strategi

Pemasaran Jamur Rimba Jaya Mushroom. "Jurnal Ilmiah Ilmu Administrasi”. Vol. 6, No. 2.

Astuti, NI Wayan Wahyu. 2013. Prospek Pengembangan Agrowisata sebagai Wisata Alternatif di Desa Pelaga. "Soshum Jurnal Sosial dan Humaniora", Vol. 3, No. 3.

Badan Pemberdayaan Masyarakat dan Pemerintahan Desa. 2015. Data Monografi Desa Mekarmanik. Pemerintah Kabupaten Bandung.

David, Fred R. 2012. Manajemen Strategis Konsep. Jakarta: Salemba Empat.

Dharmawan, I Made Adi, I Made Sarjana, dan I Dewa Ayu Sri Yudhari. 2014. Strategi Pengembangan Desa Wisata di Desa Belimbing Kecamatan Pupuan Kabupaten Tabanan. "E-Journal Agribisnis dan Agrowisata”, Vol.3 No. 2.

Direktorat Jenderal Perkebunan Kementerian Pertanian. 2015. Kebijakan Pengembangan Agrowisata di Lahan Perkebunan. Direktorat Jenderal Perkebunan Kementerian Pertanian.

Dinas Pariwisata dan Kebudayaan Provinsi Jawa Barat. 2013. Info Wisata-Agro. Dalam:http://www.disparbud.jabarprov. go.id/applications/frontend/index.php? mod=objekwisata\&act=showDetail\&catid=17. Diakses pada tanggal 24 November 2015 pukul 00.00 WIB.

Dinas Pariwisata dan Kebudayaan Provinsi Jawa Barat. 2014. Pariwisata dan Kebudayaan Jawa Barat Dalam Angka Tahun 2014. Dinas Pariwisata dan Kebudayaan Provinsi Jawa Barat. 
Dinas Perkebunan Provinsi Jawa Barat. 2014. Potensi Agrowisata Perkebunan di Jawa Barat. Dalam http://disbun.jabarprov.go.id/index.php/ artikel/detailartikel/38. Diakses pada tanggal 13 November 2015 pukul 11.00 WIB.

Hunger, J. David dan Thomas L. Wheelen. 2003. Manajemen Strategis.

Yogyakarta: Andi.

Hurriyati, Yaumil dan Sujianto. 2014. Program Pengembangan Pariwisata Air Terjun Guruh Gemurai di Kabupaten Kuantan Singingi. "Jurnal Online Mahasiswa Bidang Ilmu Sosial dan Ilmu Politik”, Vol. 1, No. 2.

Kementerian Pariwisata. 2014. Laporan Kinerja Kementerian Pariwisata 2014. Dalam:http://www.kemenpar.go.id/user files/file/LAPORAN\%20KINERJA\%20 KEMENTERIAN\%20PARIWISATA\% 20TAHUN\%202014\%20v4.pdf.

Diakses pada tanggal 05 Februari 2016 pukul 20.00 WIB.

Pinata, I Gede dan Putu G. Gayatri. 2005. Sosiologi Pariwisata. Yogyakarta: Andi.

Pitana, I Gede dan I Ketut Surya Diarta. 2009. Pengantar Ilmu Pariwisata. Yogyakarta: Andi.

Prabandari, Wijayanti Dewi. 2012. Analisis Pengembangan Potensi Agrowisata "Kopi Luwak" di Daerah Kintamani, Bangli, Bali. Dalam: http://digilib.mercubuana.ac.id/manager /file_artikel_abstrak/Isi_Artikel_701556 173097.pdf. Diakses pada tanggal 16 Januari 2016 pukul 07.00 WIB.

Primadany, Sefira Ryalita, Mardiyono, dan Riyanto. 2013. Analisis Strategi Pengembangan Pariwisata Daerah. Dalam: http://www.administrasipublik.studentjo urnal.ub.ac.id/index.php/jap/article/.../1 10. Diakses pada tanggal 01 Januari 2016 pukul 20.00 WIB.
Puspito, Atras Radifan dan Dian

Rahmawati. 2015. Faktor-Faktor yang Berpengaruh terhadap Pengembangan Kawasan Agrowisata melalui Pendekatan Community Based Tourism di Kecamatan Bumiaji Kota Batu. “Jurnal Teknik ITS”, Vol. 4, No. 2.

Putra, Suwardhana Adyaksa Anak Agung, Igusti Ngurah Apriadi Aviantara, dan I Wayan Widya. 2015. Strategi Pengembangan Agrowisata Berbasis Analisis SWOT di Unit Usaha Agro Mandiri. "BETA (Biosistem dan Teknik Pertanian)”, Vol. 3, No. 2.

Rangkuti, Freddy. 2006. Analisis SWOT: Teknik Membedah Kasus Bisnis. Cet. Ke-4. Jakarta: Gramedia Pustaka Utama.

2015. Analisis SWOT: Teknik Membedah Kasus Bisnis. Cet. Ke-20. Jakarta: Gramedia Pustaka Utama.

Rianse, Usman, dan Abdi. 2009. Metodologi Penelitian Sosial dan Ekonomi. Edisi Pertama. Bandung: Alfabeta.

Sugiyono. 2011. Metode Penelitian Kuantitif, Kualitatif, dan $R \& D$. Cet. Ke12. Bandung: Alfabeta.

Supadi, Rahab, dan Rusmusi. 2014. Kajian Mengenai Potensi dan Prospek Pengembangan Agrowisata di Kecamatan Karangreja Kabupaten Purbalingga.Dalam:http://jp.feb.unsoed .ac.id/index.php/jeba/article/viewFile/35 4/357. Diakses pada tanggal 03 Januari 2016 pukul 15.30 WIB.

Suriadikusumah, Abraham. 2014. Ekowisata dan Agrowisata (EkoAgrowisata) Alternatif Solusi untuk Pengembangan Wilayah Pada LahanLahan Berlereng di Jawa Barat.

"Student e-Journal", Vol. 3. No. 3.

Suwantoro, Gamal. 2004. Dasar-Dasar Pariwisata. Cet. 6. Yogyakarta: Andi. 
Utama, I Gusti Bagus Rai. 2011.

Agrowisata Sebagai Pariwisata

Alternatif. Dalam:

http://research.amikom.ac.id/index.php/

KIM/article/view/3521/1853. Diakses

pada tanggal 1 Januari 2016 pukul

19.00 WIB.

Windia, Wayan, dkk. 2007. Model

Pengembangan Agrowisata di Bali.

"SOCA (Socio-Economic of Agriculture and Agribusiness)", Vol. 7, No. 1.

Yodharya, Putu Decky, I Ketut Satriawan, Amna Hartiati. 2013. Strategi

Pengembangan Usaha Agroindustri

Kopi Luwak sebagai Atraksi Wisata

pada Agrowisata di Kabupaten

Tabanan. "Jurnal Rekayasa dan

Manajemen Agroindustri”, Vol. 2, No.

2. 